\title{
A KEY TO THE EGYPTIAN SUBFAMILIES OF THE FAMILY PTEROMALIDAE (HYMENOPTERA: CHALCIDOIDEA)
}

\author{
Salem, M. M.; Azab, S. A.; Al Sharkawy, A. Z. and Farghaly, D. S.
}

Plant Protection Research Institute, A.R.C., Dokki, Egypt

\begin{abstract}
A key is presented to the Egyptian subfamilies of the family Pteromalidae as they are defined at the present time, so as to facilitate recognition of the family. Included is a diagnosis of the family and illustrations of the taxonomic characters of the family and subfamilies. The key is based on material deposited in the main reference insect collections in Egypt and records from the literature.
\end{abstract}

Keywords: Hymenoptera, Pteromalidae, Chalcidoidea, Egypt.

\section{INTRODUCTION}

The Pteromalidae is one of the largest families of parasitic wasps, which occurs worldwide and currently contains about 3500 species in almost 640 genera (Noyes, 2002). This family currently contains 31 subfamilies; only 7 subfamilies are represented in Egypt (Asaphinae (1 sp), Cerocephalinae (2 spp. within 2 genera), Clorotrechinae (1 sp.), Eunotinae (3 spp. within 2 genera), Miscogasterinae (2 spp. within 2 genera), Pteromalinae (31 spp. within 23 genera) and Spalanginae (1 sp.).

The biologies and host-associations of pteromalids are extremely varied, but most species are idiobionts, many developing as ectoparasitoids of larvae and pupae of Lepidoptera, Diptera, Coleoptera and Hymenoptera. Concealed hosts, such as leaf-miners and gall-formers are commonly attacked. Other species are endoparasitoids, commonly of lepidopterous pupae. A number of pteromalids are predatory rather than parasitic, and still others are phytophagous (Graham, 1969).

The subfamily-level divisions of the family are highly contentious and unstable and were a subject for change a long time ago since Walker (1833). There have been a number of classifications proposed for the higher categories of the family, and valuable works have been made on the Pteromalidae in different parts of the world such as Westwood (1839), Förster (1856), Thomson (1876), Kurdjumov (1913),
Waterston (1921), Bouček et al (1978), Kamijo (1983), Farooqi and Subba Rao (1985), Bouček (1988 \&1991), Xiao and Huang (2000), Sureshan (2003), Sureshan \& Narendran (2000 \& 2003). Ashmead (1904) keyed out the subfamilies, tribes and genera of Pteromalidae known at that time. Whereas, Graham (1969) presented an illustrated detailed key to the families of Chalcidoidea and the family Pteromalidae was keyed to species level. Bouček (1976) prepared a key to the genera of African Pteromalidae and Bouček and Rasplus (1991) presented a key to the genera of family Pteromalidae of the Western part of the Palearctic region.

Undoubtedly, there is a great need for identification keys to many students and workers on the classification of the family Pteromalidae, museum curators and those working in the biological control related to parasitic Hymenoptera, as well as other biologists to facilitate recognition of the family.

The present taxonomic work provides diagnostic characters of the family Pteromalidae together with illustrations and an illustrated key to the subfamilies representing the family in Egypt.

\section{MATERIAL AND METHODS}

This work is based mainly on a critical examination of the available literature and reviewing the existing species of the family in the main reference insect collections in Egypt (Collection of the Plant Protection Research Institute; Collec- 
tion of the Faculty of Science, Cairo University; Collection of the Faculty of Science, Ain Shams University; Collection of Alfieri, Faculty of Agriculture, Al Azhar University and the Collection of the Egyptian Entomological Society).

The taxonomic features and terminology used herein is based on the work of Graham, 1969; Boucek, 1988; Boucek \& Rasplus, 1991). Illustrations of most taxonomic features of the family and subfamilies are provided.

The present key is so lengthy but this was unavoidable when taking into consideration the considerable range of variation in some groups.

\section{RESULTS AND DISCUSSION}

\section{Family Pteromalidae}

\section{Diagnosis:}

Small to very large chalcids, from $1-48 \mathrm{~mm}$ in length, body slender to quite robust. Most of the species are metallic green, with the head and thorax densely and reticulately punctuate. Fore and hind tarsi 5-segmented. The parapsidal grooves incomplete, and the antennae with two or three ring segments. In many species one or more of these characters may be different. The propdeum frequently has sublateral carinae, termed plicae, running longitudinally near the spiracles; posteriorly is often extended as a narrow, convex neck (nucha). Female with spurs of fore tibiae strong and long, nearly always curved but if straight then the antennal formula is different and the pronotum is relatively shorter. Antennae 8-13 segmented, antennal formula 11263, rarely 11163 . Fore wing sometimes with marginal vein short and broad. Inner orbits of eyes diverging strongly ventrad; antennae inserted distinctly above, sometimes far, below the level of the ventral edge of the eyes, postspiracular sclerite and metapleuron usually more or less hairy. Fully winged forms, with fore wing with marginal vein at least several times longer than broad,with postmarginal and stigmal vein welldeveloped, rarely quite short; speculum distinct, postmarginal vein usually as long or longer than the marginal vein; wing venation reduced. From wing base extends a vein parallel to anterior margin; the submarginal vein. Submarginal vein bends towards front margin of wing to form the prestigma. The latter continues along the wing margin forming marginal vein. Propodeum frequently bears longitudinal carinae, lateral parts being called plicae. Abdomen with first segment petiolate but sometimes short or indistinct. Internal or external parasites.

Key to the Egyptian subfamilies of the family Pteromalidae

1 Mesoscutal notauli complete (some Diparinae) or incomplete but meeting on the disc of the mesoscutum-----------------------------------------2

- Notauli neither reaching the hind margin of the mesoscutum, nor meeting on its disc------21

2 (1) Antennal toruli (fig. 7: 1) touching the lower edge of the head and situated on facial lobes which project ventrad slightly below the level of the clypeus; antennae without anelli, with seven funicular segments and a solid or three segmented clava. Mesopleuron (fig. 7:2) produced posteriorly in the form of a lamina, which completely overlaps the metapleuron; mesosternum with a broad deep median excavation (mesolcus) extending from its hind margin more than half-way towards the front of the sclerite. Propodeum with the outer rim of each spiracle partly hidden by a raised flap of the callus; postero-lateral corners of propodeum dentiform. Body black or weakly metallic; head, and dorsum of thorax excluding the propodeum, with very conspicuous piliferous punctures, the interspaces between these to a large extent, or at least those of the scutellum, with reduced microsculpture and so more or less polished. Mandibles bidentate Spalangiinae

- Antennal toruli nearly always at least slightly separated from the lower edge of the head, but if touching it then not situated on projecting facial lobes and antennae with only five or six funicular segments. Mesopleuron rarely produced posteriorly in the form of a lamina, then the lamina does not completely overlap the metapleuron; mesosternum usually with at most a narrow median longitudinal impressed line, if this line is rather broad then it is situated mainly in the front portion of the sclerite. Propodeal spiracles not overlapped by a raised flap. ---------------------3

3 (2) Ant-like species with head, thorax and 


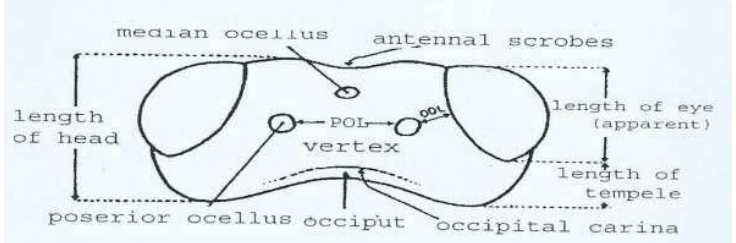

Fig. 1

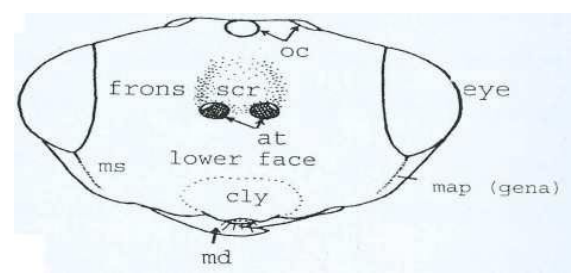

Fig. 2

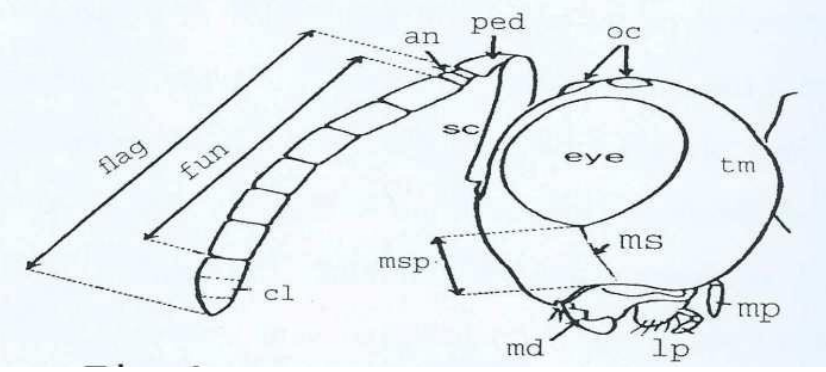

Fig. 3

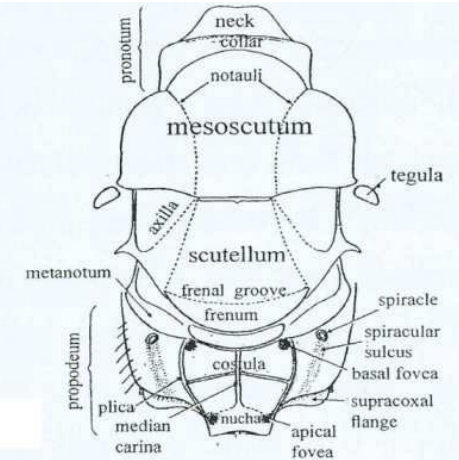

Fig. 4

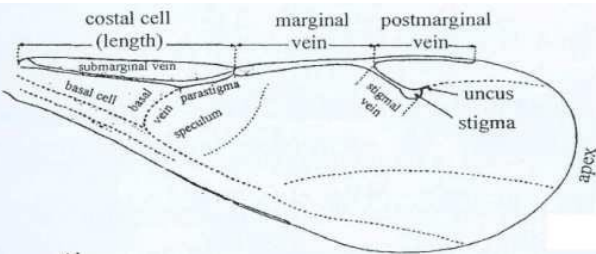

Fig. 5

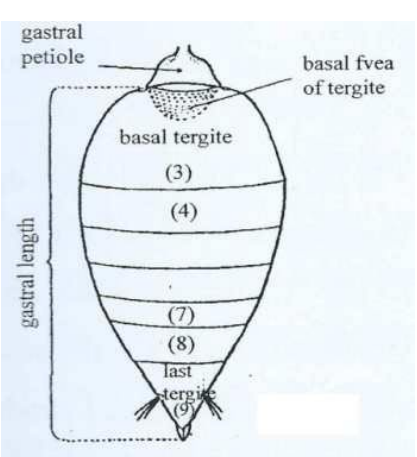

Fig. 6

Fig. (1): Dorsal view of head; Fig. (2): Frontal view; Fig. (3): Lateral view; an., anelli; at., antennal toruli; cl., clava; cly., clypeus; flag., flagellum; fun., funiculus; lp., labial palpus; md., mandible; mp., maxillary palpus; ms., malar sulcus; msp., malar space; oc., ocellus; ool., ocell-ocular distance; ped., pedicellus; pol., posterior-ocular distance; sc., scape; scr., scorbes. Fig. (4): Dorsal view of thorax; Fig. (5): Forewing; Fig. (6): Petiole and gaster. 


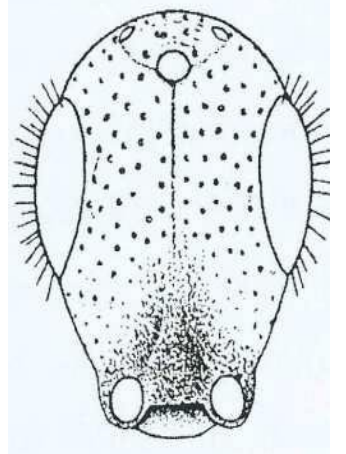

1

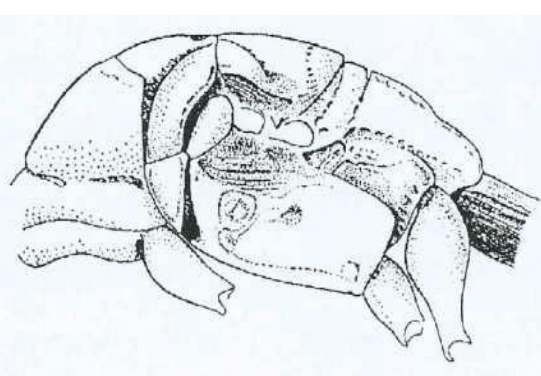

2

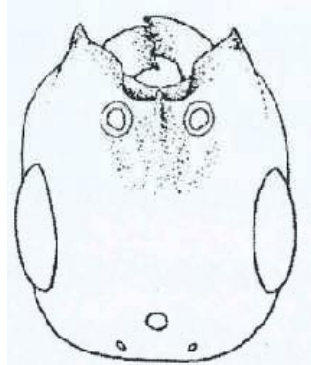

3

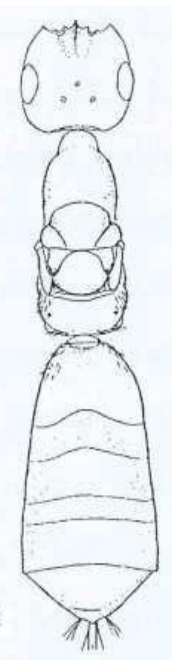

4

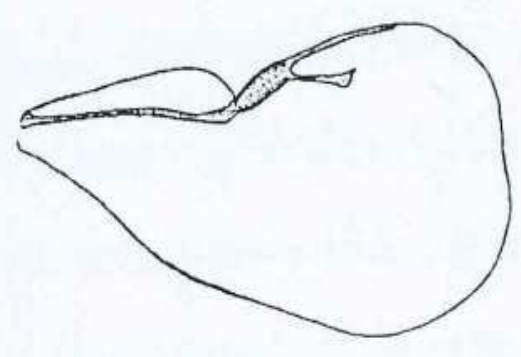

5

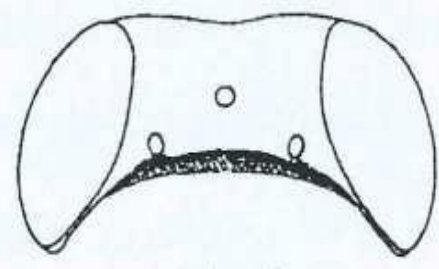

6
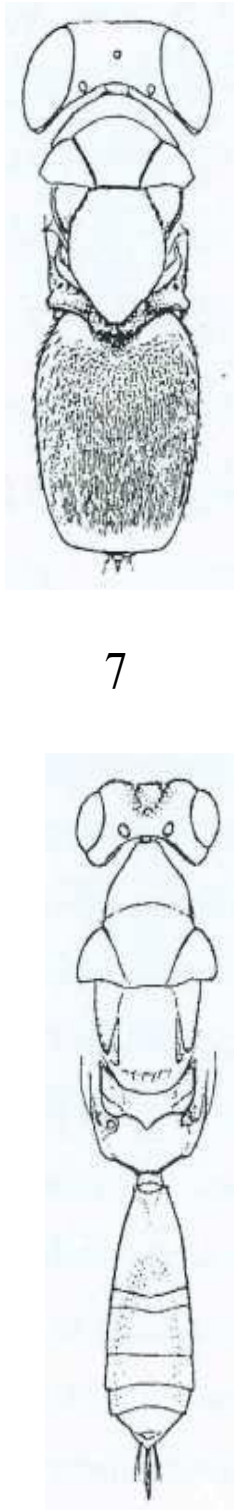

7

1)

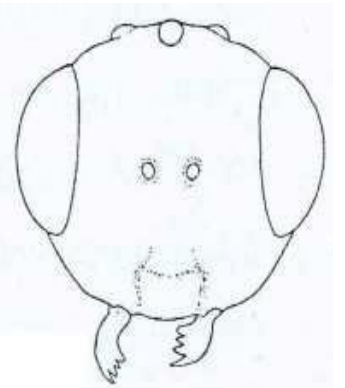

9

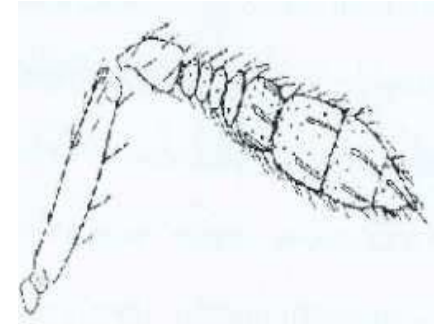

10 


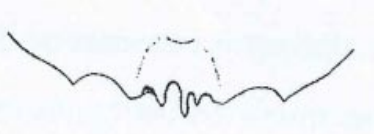

12

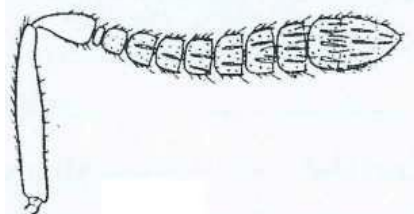

16

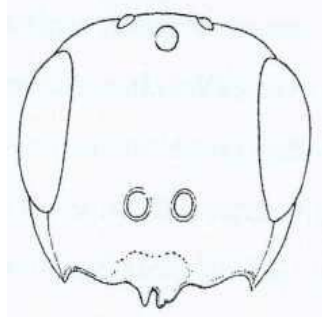

13

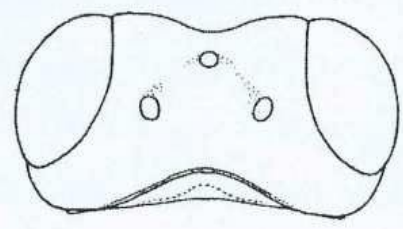

14

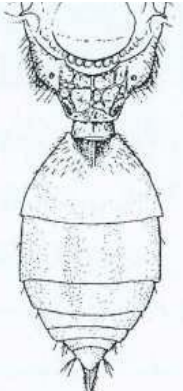

15

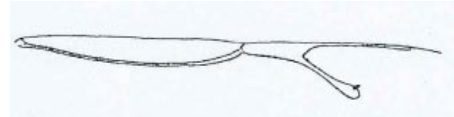

17

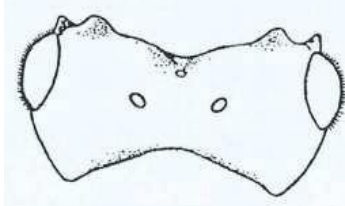

18

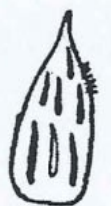

19

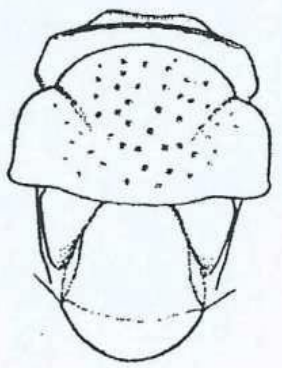

20

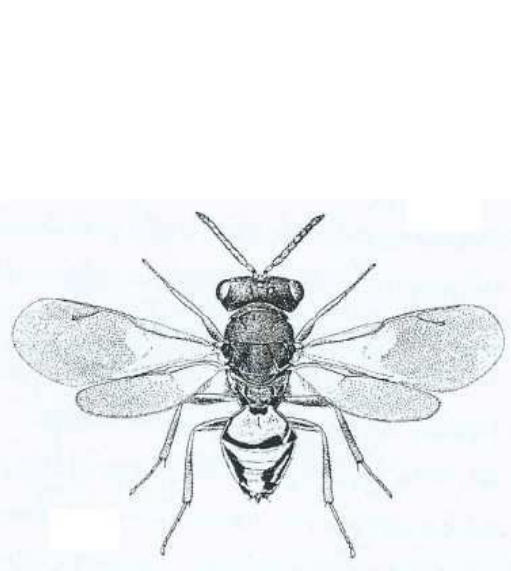

21

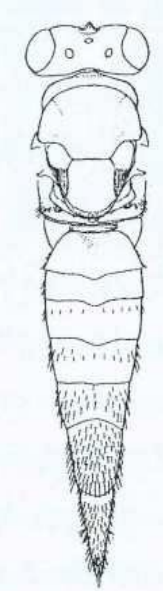

22

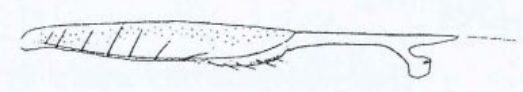

23

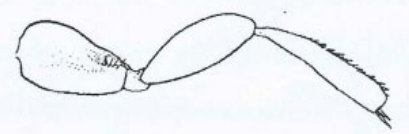

24

Fig. (7): 1 \& 2 Subfamily Spalanginae ; 3 \& 4 Subfamily Cerocephalinae; 5 \& 6 \& 7 \& 8 \& 9 Subfamily Eunotinae; 10 \& 11 \& 12 \& 13 Subfamily Miscogastrinae ; 14 \& 15 \& 16 Subfamily Asaphinae; 17 $\& 18 \& 19 \& 20 \& 21$ Subfamily Pteromalinae $; 22 \& 23 \& 24$ Subfamily Colotrechninae. 
Salem, M. M et al .

gaster all at least partly testaceous. Face, on either side of the clypeus, often with a tubercle, crest or forwardly-projecting tooth (fig.7: 3), sometimes with a second crest on each side just below the level of the antennal toruli; malar sulcus absent. Antennae 8 to 11 -segmented, without anelli or, some males only, with one anellus. Propodeal spiracles separated by much more than their own length from the hind margin of the metanotum (fig.7: 4). Wings sometimes vestigial; when developed having the marginal vein very long, the stigmal vein short, the postmarginal vein equal to or shorter than the stigmal; parastigma with a callus which often bears a conspicuous tuft of dark bristles Cerocephalinae

- species rarely ant-like; head, thorax and gaster rarely all testaceuous-marked, face has neither crests nor teeth. Antennae often with a different formula. Propodeal spiracles rarely separated by more than their own length from the hind margin of the metanotum$-4$

4 (3) Macropterous; front edge of costal cell of fore wing (fig.7: 5) strongly curved apically, so that the wing appears excised at the point where the submarginal vein meets the marginal vein -------------- Eunotinae (part)

- Either the front edge of costal cell of fore wing in its apical portion is straight or at most weakly sinuate; or the species is brachypterous

5 (4) head (fig. 7: 6) with posterior ocelli touching the occipital edge, which is sharp; head in front view subtriangular; genae long to very long. Scutellum large, slightly to considerably longer than the mesoscutum, sometimes more or less overlapping the gaster. Fore wing with postmarginal vein usually at most as long as, rarely slightly longer than, the stigmal vein. First tergite of gaster very large, usually concealing the remaining tergites propodeal callus with a raised longitudinal crest which ends posteriorly in a tooth. Antennae 8- to 10-segmented, inserted at least slightly below the level of the ventral edge of the eyes, (fig. 7: 7) Eunotinae (part)

- head with posterior ocelli do not touch the occipital edge, head is not subtriangular, the genae are short, the scutellum is smaller, and the other characters do not all agree with the above.
Head in front view more often more or less oval; scutellum rarely distinctly longer than the mesoscutum, not overlapping the gaster. Fore wing with postmarginal vein often longer than the stigmal. First tergite of gaster rarely occupying more than half the total length; propodeal callus rarely with a longitudinal ridge. Antennal formula often otherwise 6

6 (5) Wings bitten off somewhere near their bases, so that the venation, except part of the submarginal vein, is missing

\section{Asaphinae (part)}

- Wings fully developed with complete venation

7 (6) Fore wing with marginal vein conspicuously thickened, either throughout, or in its prox-

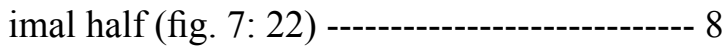

- Fore wing with marginal vein not conspicuously thickened. Note: the parastigma, which may be thickened, is not counted as part of the marginal vein ---------------------------------------10

8 (7) Clypeus with at most a trace of strigose sculpture at the sides, its anterior margin subtruncate; hind tibia with one spur; antennal formula 11263 (fig. 7: 8 \&9) Eunotinae (part)

- Either the clypeus is wholly radiately strigose or its anterior margin is bilobed, and the hind tibia has two spurs; or the antennal formula is different --------------------------------- 9

9 (8) Either the head and thorax are yellow and black, non-metallic; or the antennal formula is 11173 Miscogasterinae (part)

- Head and thorax usually metallic, if nonmetallic then without yellow markings; antennal formula otherwise Pteromalinae (part)

10 (7) Males only with eyes very large and dorsally touching or almost touching the posterior ocelli, but their inner orbits diverging strongly ventrad. Antennae (fig. 7: 10) very short: either with two anelli and three funicular segments; or three anelli and two funicular segments, or four anelli but only one funicular segment. Small species, at most $2 \mathrm{~mm}$. in length Miscogasterinae (part)

- Either females or males with eyes smaller 
and not nearly touching the posterior ocelli dorsally, and the other characters not all present simultaneously. Males with inner orbits diverging strongly have longer antennae, with either one anellus and seven funicular segments; or no anelli but eight funicular segments $-11$

11(10) Antennae 10, 11, or 12-segmented if with two anelli, then only five funicular segments; sometimes three or four anelli but in that case at most three funicular segments; often only one anellus but then at most six funicular segments. Propodeum without a nucha, its petiolar foramen bounded by a simple ridge; propodeum, medially, not or hardly produced caudad the bases of the hind coxae; supracoxal flanges, except in a few species, very narrow and linear. Anterior margin of clypeus rarely with teeth. Postmarginal vein of fore wing shorter than, and only rarely longer than, the marginal vein. Petiole of gaster smooth, usually more or less transverse, rarely as long as broad (fig. 7: 11)

\section{Miscogasterinae(part)}

- Antennae 13-segmented; most often with two anelli and six (occasionally seven) funicular segments, or three anelli and five funicular segments; occasionally with only one anellus, but then with seven funicular segments. Petiolar foramen of propodeum most often bounded by a more or less crescentic, smooth or transverselyaciculate strip; or with a convex, reticulate nucha. Propodeum, medially is often produced caudad the bases of the hind coxae; the supracoxal flanges, are not very narrow and linear. Anterior margin of clypeus often with teeth. Postmarginal vein of fore wing often longer than the marginal vein. Petiole of gaster often distinctly sculptured, sometimes longer than broad $-12$

12 (11) Body either brown to black and nonmetallic; or else the head and thorax at least partly yellow to reddish

\section{Miscogasterinae(part)}

- Body at least slightly metallic; head and thorax without yellow or reddish markings-------13

13 (12) Genae with a sharp edge or border which extends well up the temples; occiput also margined (fig. 7: 14). Pronotum (fig. 7: 15) large and subrectangular. Antennae inserted below level of ventral edge of eyes, antennal formula 11263 or 11173 (fig. 7: 16) - Asaphinae (part)

- Genae without a sharp edge except sometimes near the mandibles, in which case the occiput is not margined, while the pronotum is shorter and not subrectangular, and the antennae are inserted higher on the head $-14$

14 (13) Postmarginal vein of fore wing shorter than the marginal vein. Antennae inserted well below the level of the ventral edge of the eyes, 11263 in male, 11353 in female. Anterior margin of clypeus without teeth --- Asaphinae (part)

- Either the postmarginal vein of the fore wing is at least slightly longer than the marginal vein; or else the antennae are inserted level with or above the ventral edge of the eyes.Antennal formula sometimes otherwise. Anterior margin of clypeus often with a tooth or teeth----------15

15 (14) Fore wing with postmarginal vein at least slightly longer than the marginal vein-- 16

- Fore wing with postmarginal vein not longer than the marginal vein ------------------ 18

16 (15) Postspiracular sclerite narrow; clypeus wholly strigose

\section{Pteromalinae (part)}

- Postspiracular sclerite large and broad; clypeus either mainly to entirely reticulate, or smooth----------------------------------------------17

17 (16) Occiput margined, at least medially

\section{Pteromalinae (part)}

- Occiput not margined..........Miscogasterinae (part)

18(15) Anterior margin of clypeus with three asymmetric teeth (fig. 7: 12), or with two teeth of which the left-hand one is more or less bifid (fig. 7:13) Miscogasterinae (part)

- Anterior margin of clypeus either edentate or, if teeth are present, they are neither asymmetrically placed nor bifid19

19 (18) Petiole of gaster strongly sculptured, reticulate or strigose, often more or less rectangular, or longer than broad..........Miscogasterinae (part) 
- Petiole of gaster smooth or nearly so, usually more or less transverse though sometimes as long as broad$-20$

20 (19) Antennae inserted low down, their toruli not or hardly above the level of the ventral edge of the eyes, 11263. Clypeus without, or with at most some vague striae.

Miscogas-

\section{terinae (part)}

- Either the antennae are inserted distinctly above the level of the ventral edge of the eyes; or else their formula is 11353; or the clypeus has numerous radiating striae Pteromalinae (part)

21 (1) Face and/or frons with a crest or tubercle on each side (fig. 7: 18); or the outer edges of the deep antennal scrobes are raised to form crests. Pteromalinae (part)

- Face and frons without crests or tubercles, the interantennal tubercle, which is sometimes carinate, is not counted; outer edges of antennal scrobes not crested, the scrobes often shallow----

22 (21) Brachypterous or apterous species

\section{Pteromalinae (part)}

- Macropterous species$-23$

23 (22) Antennae 10, 11, or 12-segmented $-24$

- Antennae 13-segmented $-25$

24 (23) Antennae without anelli or with only one anellus; clava neither acutely pointed nor with an apical process, two- or three-segmented

\section{Miscogasterinae (part)}

- Antennae with two or three anelli; clava (fig. 7: 19) acutely pointed, acuminate, or with an apical process, usually solid or indistinctly segmented -

\section{Pteromalinae (part)}

25 (23) Axillae (fig. 7: 22) produced forwards far in advance of the scutellar base, the latter broad. Fore wing (fig. 7: 23) with stigmal vein very short, the stigma almost sessile, marginal vein three to four times as long as the stigmal vein, postmarginal vein relatively short. Hind tibiae (fig. 7: 24) somewhat compressed, their posterior edge with a row of spines, two strong apical spurs present of which the second is only slightly shorter than the first; hind coxae very long, at least three quarters as long as their femora, the latter compressed. Spiracles of propodeum touching the metanotum, the latter often covering the front part of the spiracular rim. Last two or three segments of female gaster clothed with dark bristles. Antennal formula 11263 in female, 11353 in male.

Colotrechninae

- Axillae very rarely produced so far in advance of the scutellar base, if so then the latter is narrower. Venation of fore wing usually quite unlike the above, if somewhat similar then the hind tibiae have no spines along their posterior edge, and have only one apical spur, whilst the hind coxae are relatively shorter and the propodeal spiracles are at least slightly separated from the metanotum--------------------------------- 26

26 (25) Antennae inserted low on the head, not or hardly above the level of the ventral edge of the eyes; axillae meeting or nearly meeting, so that the scutellum touches the mesoscutum only on a narrow base or at a point; clypeus reticulate or smooth. Miscogasterinae (part)

- Antennae inserted higher, distinctly above the level of the ventral edge of the eyes; axillae (fig. 7: 20) widely separated, so that the scutellum touches the mesoscutum on a broad base; clypeus most often striate ..... Pteromalinae (part)

\section{REFERENCES}

Ashmead, W. H. (1904): Classification of the chalcid flies or the superfamily Chalcidoidea, with descriptions of new species in the Carnegie Museum, collected in South America by Herbert H. Smith. Mem. Carneg. Mus. 1(4): i-xi, 225-551.

Bouček, Z. (1976): African Pteromalidae (Hymenoptera): new taxa, synonymies and combinations. J. Ent. Soc. S. Afr., 39(1): 9-31.

Bouček, Z. (1988): Australasian Chalcidoidea (Hymenoptera). A biosystematic revision of genera of fourteen families, with a reclassification of species. Australasian Chalcidoidea Hymenoptera A biosystematic revision of genera of fourteen families, with a reclassification of species. C.A.B. International, Wallingford: 1-831.

Bouček, Z. (1989): Australasian Chalcidoidea (Hymenoptera): errors and omissions. Entomologist'-s-MonthlyMagazine, 125(1496-99): 85-86. 
Bouček, Z. (1991): Four new genera of Pteromalidae (Hymenoptera), with some taxonomic changes. Boll. Zool. agr. Bachic., 22:195-206.

Bouček, Z. (1993): New taxa of North American Pteromalidae and Tetracampidae (Hymenoptera), with notes. J. Nat. Hist., 27(6): 1239-1313.

Bouček, Z. \& Rasplus, J. Y. (1991): Illustration key to West- Palearctic genera of Pteromalidae ( Hymenoptera: Chalcidoidea). Institute National de la Recherche Agronomique, Paris, $140 \mathrm{pp}$.

Bouček, Z.; Subba Rao, B. R. and Farooqi, S. I. (1978): A preliminary review of Pteromalidae (Hymenoptera) of India and adjacent countries. Oriental-Insects, 12(4): 433-468.

Farooqi, S. I. and Subba Rao, B. R. (1985): The chalcidoidea (Insecta: Hymenoptera) of India and the adjacent countries. Part 1. Review of families and keys to families and genera, Orient. Insects, 19: $161-310$.

Forster, A. (1856): Hymenopterologische Studin. 2. Heft. Chalcidae und Proctotrupii. 152 pp.

Graham, M. W. R. (1969): The Pteromalidae of NorthWestern Europe (Hymenoptera: Chalcidoidea). Bulletin of the British Museum (Natural History) Entomology, Supplement 16: 908 pp.

Kamijo, K. (1983): Pteromalidae (Hymenoptera) from Korea, with description of four new species. AnnalesHistorico-Naturales-Musei-Nationalis-Hungarici， 75:
295-311

Kurdjumov, N. V. (1913): Notes on Pteromalidae (Hymenoptera, Chalcodoidea). Russk. Ent. Obozr. 13: 1-24.

Noyes, J. S. (2002): Interactive Catalogue of World Chalcidoidea. Electronic Publication.

Sureshan, P. M. (2003): Pteromalinae (Pteromalidae: Chalcidoidea: Hymenoptera) of Indian subcontinent. Occasional-Paper-Records-of-the-Zoological-Survey-of-India., (205): 1-170.

Sureshan, P. M. \& Narendran, T.C. (2000): Pteromalidae (Chalcidoidea: Hymenoptera) from India with the description of a new species. Entomon., 25(2): 117-128.

Sureshan, P. M \& Narendran,T.C. (2003): A checklist of Pteromalidae (Hymenoptera: Chalcidoidea) from the Indian subcontinent. Zoos'-Print, 18(5): 1099-1110.

Thomson (1876): Hymenoptera Scandinaviae. Tom. IV. Pteromalus (Svederus). $259 \mathrm{pp}$.

Walker, F. (1833): Monographia Chalciditum. Ent. Mag., 1: 367-384, 455-466.

Waterston, J. (1921): Report on parasitic Hymenoptera, bred from pests of stored grain. Rep. Grain Pests Comm. R. Soc., 9: 8-32.

Westwood, J. O. (1839): Synopsis of the genera of British insect, pp.49-80. [Issued with: An introduction to the modern classification of insects, no. 13].

Xiao, H.and Huang, D. W. (2000): A taxonomic study on Pteromalidae (Hymenoptera) from Hainan, China. Entomotaxonomia., 22(2): 140-149. 